\title{
Evaluation of Transit Signal Priority on Arterial Performance - A Comparison between Conventional and Unconventional Intersection Operation
}

\author{
Taqwa Alhadidi \\ Department of Civil Engineering, Al-Ahliyya Amman University, Jordan
}

Received December 24, 2020; Revised July 1, 2021; Accepted July 19, 2021

\section{Cite This Paper in the following Citation Styles}

(a): [1] Taqwa Alhadidi, "Evaluation of Transit Signal Priority on Arterial Performance - A Comparison between Conventional and Unconventional Intersection Operation," Civil Engineering and Architecture, Vol. 9, No. 5, pp. 1615-1626, 2021. DOI: 10.13189/cea.2021.090531.

(b): Taqwa Alhadidi (2021). Evaluation of Transit Signal Priority on Arterial Performance - A Comparison between Conventional and Unconventional Intersection Operation. Civil Engineering and Architecture, 9(5), 1615-1626. DOI: 10.13189/cea.2021.090531.

Copyright $\bigcirc 2021$ by authors, all rights reserved. Authors agree that this article remains permanently open access under the terms of the Creative Commons Attribution License 4.0 International License

\begin{abstract}
Transit Signal Priority (TSP) shows capability to improve traffic operations through providing transit vehicles a higher priority to cross intersections. However, implementing TSP could impose extra delays to the adjacent traffic. Specifically, TSP imposes extra delay on turning traffic that could be solved by converting the intersections to unconventional intersection. To do so, this paper models assesses and evaluates the possibility for implementing a TSP in arterial roadway in Amman, capital of Jordan, by using real traffic data under different scenarios including conventional and unconventional intersection designs. The evaluation was done using simulation. Simulation results show that the TSP implementation reduces system travel time and improves the overall system delay. Specifically, implementing the combination of TSP with unconventional intersection design reduces corridor travel time, system delay, and queue length. Moreover, simulation results indicated that applying TSP improves individual movements travel time and delay up to $35 \%$ per vehicle.
\end{abstract}

Keywords Transit Signal Priority, Microscopic Simulation, Median-U-Turn, VISSIM

\section{Introduction}

Currently, urban networks globally suffer from longer travel time and queues, increasing in delay, higher emissions, and lower travel speed. Several methods have been adopted to address urban traffic congestion by either using conventional methods (i.e. adjusting cycle length timing and phasing) or using the Unconventional Arterial Intersection Designs (UAIDs). Not surprisingly, results from the field show that the most promising option to handle this problem is deploying intelligent transportation system (ITS) applications. ITS incorporates any application that improves the efficient movement of individuals and goods by implementing different technologies. As a result of their success, different ITS applications have been implemented globally. According to the most state-of-practice, the most important of these are improving the public transportation system via Advanced Public Transportation Systems (APTSs) and implementing adaptive Traffic Signals (ATSs). ATS aims to improve intersection performance by minimizing delays at traffic signals, which is considered an important factor in network travel time. Deploying Bus Rapid Transit (BRT) systems as an APTs enhances life quality, reduces travel time and dwell time, and provides a cost-effective transportation mode in urban area as compared with the light rail projects. BRT is defined as an "enhanced bus system that operates on bus lanes or other transit ways in order to combine the flexibility of buses with the efficiency of rail. It also utilizes a combination of advanced technologies, infrastructure and operational investments that provide significantly better service than 
traditional bus service" [1]. BRT is a popular mode of transportation in more than 160 cities worldwide where building light rail is impossible due to the limitation in the available right-of-way (ROW). BRT is able to carry nearly 30 million daily passenger trips [2]. BRT can be considered as a promising solution for congested urban network due to its characteristic by separate its movement from another traffic vehicles by providing dedicated lane for BRT movement.

Jordan is one of the middle east countries which suffers a large transportation problem after hosting many refugee's due to the latest events in the region. Thus, create a massive problem for transportation system due to a sudden change in demand without providing a capable infrastructure to carry the explosion in demand. With this in mind, Greater Amman Municipality (GAM) start initiating Bus Rapid Transit in Amman, the capital of Jordan, that has over of 4 million inhabitants which are constituted about $42 \%$ out of Jordan population [3].

Amman BRT scheme focuses on providing reliable service along the most production/attraction zones in
Amman including employee of public institutes like GAM, and other types of public area services department in Amman, University of Jordan students and employees, school students and other captive riders. Accordingly, Amman's BRT scheme focuses on the heaviest corridor in Amman including; line 1,2 and 3, which are shown in Figure 1.

This study has twofold, first evaluated the performance of BRT in Amman by using VISSIM as a microscopic simulation model for performance evaluation. Second, evaluate signalized roundabout performance serving BRT and coordinated with another two successive congested intersections.

In the following sections, this paper starts with a summarization for the existing state-of-art and state-of-practice are presented in Section 2. Section 3 introduces the research methodology in additional to the data description. Then, the simulation results are presented based on three different scenarios. Finally, the paper ends up with a summary of key findings and recommendations to future research.

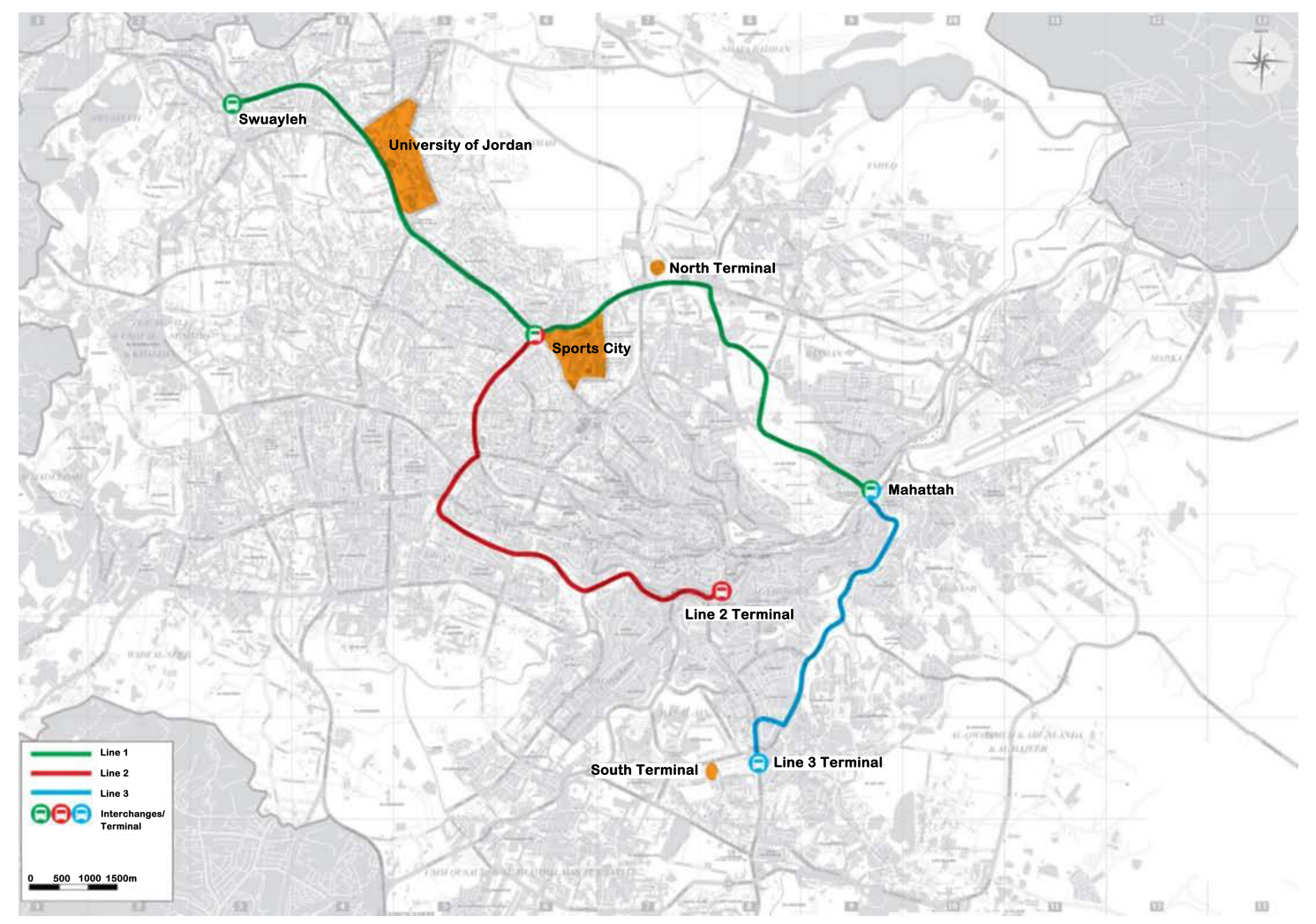

Figure 1. Amman BRT Lines (4) 


\section{Literature Review}

Providing transit with special treatment helps in improving schedule adherence, increasing ridership, and deceasing delay for riders and network.

Transit Signal Priority (TSP) system is used to facilitate the transit movements along intersections to get an efficient transit schedule [4]. TSP has been widely implemented in different areas by researchers and agencies around the world to evaluate the TSP system impacts on buses and general traffic as well. Most of the previous studies have shown significant improvements in terms of measures of effectiveness (MOES) using TSP such as transit travel time, delays, side-street queue length [5-7]. Some studies evaluated the TSP on different area's types such as an isolated intersections and arterial areas. Also, some of the previous studies considered different signal control types such as fixed-time, actuated, and responsive or adaptive control [8].

Sam et al. [9] proposed a procedure for real-time signal control that considers transit interference and priority. The procedure generates a number of short-term alternative real-time phase sequences for various levels of transit priority. A traffic-responsive control was developed with transit priority by generating control strategies based on some priority lists [9]. The model tested in the afternoon peak hour for an intersection of Queen Street and Bathurst Streets. The results showed that there was a delay reduction compared with fixed-time operation.

A Stochastic mixed-integer nonlinear program (SMINP) model was proposed as the core component of a real-time Transit Signal Priority (TSP) control system [10]. The model used a novel approach to capturing the impacts of the priority operation to other traffic using the deviations of the phase split times from the optimal background split times. The SMINP model was implemented in a VISSIM microscopic traffic model with an optimization solver. The aim of this study was to minimize the delay of bus system [10]. The results showed that there was a significant improvement with bus delay comparing with RCB- TSP in a single-bus case. Moreover, the bus priority using the proposed model was much more efficient under congested traffic conditions for a multiple-bus case.

Dion et al. Applied TSP along Columbia Pike arterial corridor, in Arlington, VA [5]. The study used the INTEGRATION microscopic traffic simulation model to evaluate the impact of different priority strategies on buses and general traffic during the morning peak and midday traffic periods. The transit priority strategies include regular and express buses. The priority logic that is considered in the study provides simple green extensions and green recalls within a fixed-time traffic signal control [5]. The simulation results showed that the buses provided with priority would benefit from TSP. The results also showed that when the less demand is present, the overall negative impacts could be negligible due to the availability of spare capacity. The results also indicated that the buses experience reduced travel time, delay, stops, and fuel consumption. Another study applied TSP in Broad Street in Newark, New Jersey. This arterial is characterized by significant transit activity and heavy traffic volumes. The results showed that the travel time in both cross and major streets were reduced. Results also showed that the benefits of TSP can reduce the number of buses in the network. Another study evaluated the TSP impacts on the operations of a single signalized intersection within a coordinated arterial system [6]. The objective of this study is to isolate the impacts of various traffic, transit, and signal timing factors on the potential benefits of TSP. The results showed that TSP provides benefits to transit vehicles that receive priority [6]. The results also showed that the system-wide impact of TSP is dependent on the frequency of transit vehicles. As the transit vehicle frequency increases, larger system disbenefits are noticed. Another interesting finding is that the transit vehicle dwell times at nearside bus stops can have significant systemwide impacts on the benefits of TSP [6].

A green extension TSP was implemented to test the system-wide impacts on U.S. Route 1 in the Northern Virginia Area [11]. The corridor is controlled by a coordinated-actuated signal control with a cycle length of $180 \mathrm{~s}$. The green time can extend $5 \mathrm{~s}$ if the system detects any transit vehicle that needs more time than the normal green to pass the intersection. The extended green value is subtracted from the next phases in the same cycle and hence the cycle length will not be affected, and it would be constant [11]. The results showed that the buses always benefited from the TSP but did not guarantee a system-wide benefit. The results also indicated that the use of green extension TSP does not improve the transit vehicle nor system-wide system. Another interesting finding in this study is that TSP operations at near-side bus stops specifically within the detection zone results in increasing the bus delays [11]. Kim et al. studied the effect of nearside bus stops on the TSP system [12]. The study proposed a Weighted-Least-Squares (WLS) regression model to estimate the transit vehicle dwell time at the bus stops and considered also the prediction interval. This study considered three different variables that could affect the dwell time such that schedule adherence, passenger loads, and bus headways. A t-test statistical analysis was conducted to test the statistical significantly impact for each variable. The statistical analysis showed that the bus headways have a linear relationship with bus dwell time for all bus stops but not with schedule adherence and passenger loads [12]. The proposed model was tested on VISSIM model of an urban arterial section of Bellaire Boulevard in Houston, TX. The results showed that the dwell time for buses at nearside bus stops can be modeled using WLS regression. The delays for buses were improved using the proposed algorithm [12]. 


\section{Methodology}

The current state-of-art and state-of-practice reported the impact of the TSP under conventional intersection design. Ironically, most of the state-of-art indicated that the TSP has a negative impact on the turning vehicle traffic. Thus, implementing the unconventional intersection design could help in eliminating the TSP impact on the left-turning traffic. This section starts with describing the difference between the conventional and unconventional intersection design, followed by the site description and data collection. Then, microscopic simulation model development was presented for both conventional and unconventional intersection.

\section{Conventional and Unconventional Intersection Design}

In an attempt to reduce traffic congestion agencies and engineers have explored and utilized Unconventional Arterial Intersection Designs (UAIDs) by compromising two design considerations the first one is improving network performance and the second one is reducing construction and operation cost towards improving mobility for roadway users. The general management strategy and operational principle of the UAID implementation consists of reduction in the number of signal phases, restriction the left turn movement across the main intersection and emphasize the through traffic movement and improving intersection operational efficiency and safety by reducing the total number of conflict points. Numerous UAID types had been implemented in countries including USA, Mexico and Europe these intersections are Median U-Turn, Superstreet, and Quadrant Intersection [18]. In a previous works by the author, different UIADs have been found to be a promising solution in the heavy traffic status especially in Amman [13], [14]. One of the success schematics of the UAIDs that have been used widely is the Median U Turn (MUT). The MUT is the most common unconventional design in the USA; it has been implemented successfully in Maryland, Florida, Louisiana, and New Jersey [18]. The primary objective of the MUT design is to remove all left turn traffic from the main intersection. Left turn movements are converted to right turns at the intersection then, using a unidirectional median crossover to make a U-turn on the major highway then drivers may complete their change in direction. It includes multiple signal illustrations (typically three, one for main intersection (controlled by a 2-phase cycle) and one (coordinated) for each of the two median crossovers). This would favor the major street though movements because time from the signal cycle does not have to be allocated to protect left turn phases. The design removes or relocates all conflicts that would normally be associated with left turn movements. Figure 2 shows a MUT design. The MUT has been studied by several researchers. Reid and Hummer [19] compared the MUT design with a conventional intersection design. They constructed a model of a typical corridor in a suburban area near Detroit using a real traffic data. The results showed that the MUT intersection reduced system travel time by $17 \%$ and increased the system speed about $25 \%$ compared with the conventional intersection.

Hummer and Reid [19] reviewed MUT characteristics and summarized new information about the intersection and suggested when it should be feasible to use. Bared and Kaiser [20] compared the MUT with conventional intersection, the MUT showed a considerable saving in delay time, due to two phase signals with reduction in cycle length and it was found that the capacity has improved about 18 percent when compared with the conventional intersection.

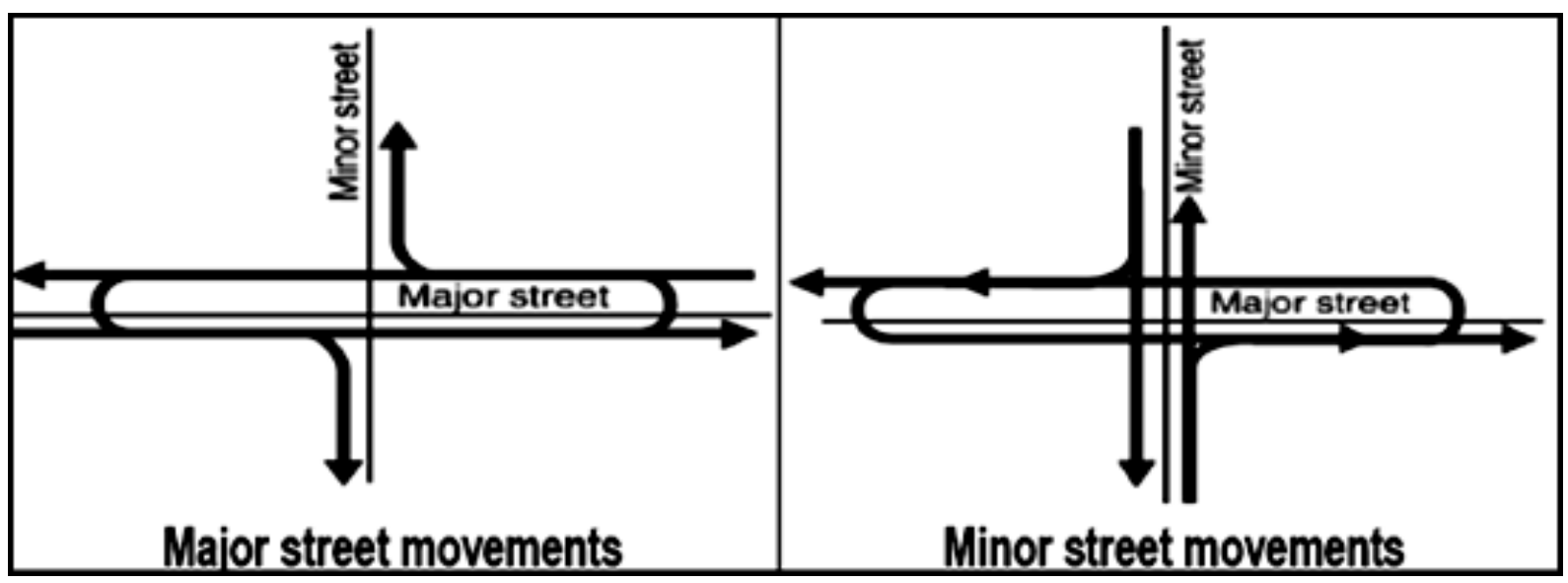

Figure 2. Median U-Turn Schematic [18] 


\section{Site Description}

Figure 3 shows an aerial photo of the study area and the adjacent attractions. The study area consists mainly of three intersections, Wadi Saqra Intersection, AlKindi Intersection, and the Fifth Circle Intersection. The segment length is about $1 \mathrm{Km}$ in length with a posted speed of $60 \mathrm{Km} / \mathrm{hr}$. Alkindi intersection accommodates traffic from Om Othaina Southbound and Alshmesani along East-West bound. Wadi Saqra carries the traffic from downtown Southbound, Allouibdeh from Northbound and Alshmesani East-West Bound. Moreover, Fifth Circle carries the traffic along major arterial roads from Alshmesani along east-west bound and the heaviest traffic along the longest arterial road on North-South bound.

\section{Traffic Volumes}

The key traffic data were available from the department of traffic operations at GAM. Traffic data were collected at the three intersections in February 2018. The 15-min peak hour volumes occurred in the morning peak from 7:45 to $8: 45 \mathrm{Am}$. The data included traffic volumes for each direction including left and right turning volumes, gradients, and percentages of heavy vehicles (H.V\%) as shown in Table 1, 2, and 3 for Alkindi Intersection, Wadi Saqra Intersection and Fifth intersection, respectively.

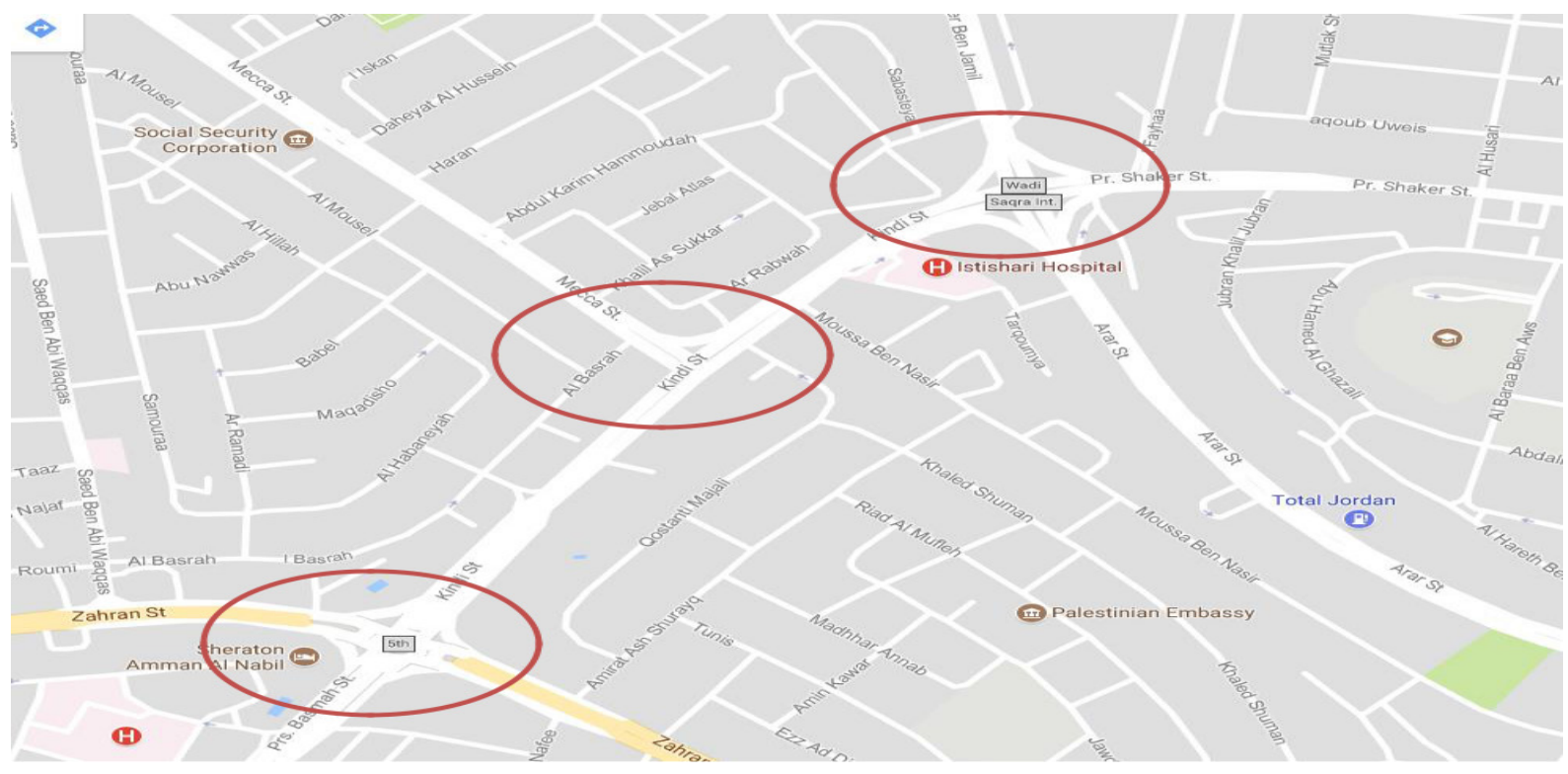

Figure 3. Site map (google map, 2020)

Table 1. Alkindi Intersection Counting Volume. (GAM)

\begin{tabular}{|c|c|c|c|c|c|c|}
\hline \multirow{2}{*}{ Approach } & \multicolumn{2}{|c|}{ Southbound } & Westbound & & Eastbound & \\
\cline { 2 - 7 } & Left & Right & Through & Right & Through & Left \\
\hline Volume & 1,257 & 481 & 2,049 & 1,535 & 900 & 1,830 \\
\hline PHF & 0.94 & 0.884 & 0.92 & 0.9 & 0.89 & 0.97 \\
\hline Grade & $-6 \%$ & & $5 \%$ & & & \\
\hline H.V & \multicolumn{2}{|c|}{$1.53 \%$} & $2.02 \%$ & & & $1.53 \%$ \\
\hline
\end{tabular}

Table 2. Wadi Saqra Intersection Counting Volume (GAM)

\begin{tabular}{|c|c|c|c|c|c|c|c|c|c|c|c|c|}
\hline \multirow{2}{*}{ Approach } & \multicolumn{2}{|c|}{ Eastbound } & \multirow[b]{2}{*}{ Right } & \multicolumn{2}{|c|}{ Westbound } & \multirow[b]{2}{*}{ Right } & \multicolumn{2}{|c|}{ Southbound } & \multirow[b]{2}{*}{ Right } & \multicolumn{3}{|c|}{ Northbound } \\
\hline & Through & Left & & Through & Left & & Through & Left & & Through & Left & Right \\
\hline $\begin{array}{l}\text { Volume } \\
\text { (Vph) }\end{array}$ & 1,947 & 897 & 500 & 792 & 540 & 266 & 553 & 423 & 195 & 793 & 795 & 302 \\
\hline PHF & 0.91 & 0.67 & 0.68 & 0.93 & 0.94 & 0.8 & 0.87 & 0.85 & 0.86 & 0.92 & 0.83 & 0.7 \\
\hline Grade & \multicolumn{3}{|c|}{$-3 \%$} & \multicolumn{3}{|c|}{$-9 \%$} & \multicolumn{3}{|c|}{$-7 \%$} & \multicolumn{3}{|c|}{$5 \%$} \\
\hline H.V & \multicolumn{3}{|c|}{$2 \%$} & \multicolumn{3}{|c|}{$1.30 \%$} & \multicolumn{3}{|c|}{$3 \%$} & \multicolumn{3}{|c|}{$3 \%$} \\
\hline
\end{tabular}


Table 3. Fifth Intersection Counting Volume (GAM)

\begin{tabular}{|c|c|c|c|c|c|c|c|c|}
\hline & \multicolumn{2}{|c|}{ Northbound } & \multicolumn{2}{c|}{ Southbound } & \multicolumn{2}{c|}{ Westbound } & \multicolumn{2}{c|}{ Eastbound } \\
\hline & Through & right & Through & Right & Through & Right & Through & Right \\
\hline $\begin{array}{c}\text { Volume } \\
\text { (vph) }\end{array}$ & 687 & 180 & 1,584 & 595 & 1,595 & 595 & 689 & 663 \\
\hline PHF & 0.867 & 0.937 & 0.87 & 0.79 & 0.89 & 0.83 & 0.96 & 0.86 \\
\hline Grade & \multicolumn{2}{|c|}{$0 \%$} & \multicolumn{2}{|c|}{$0 \%$} & \multicolumn{2}{|c|}{$-1 \%$} & \multicolumn{2}{|c|}{$2 \%$} \\
\hline H.V & \multicolumn{2}{|c|}{$1 \%$} & \multicolumn{2}{|c|}{$4 \%$} & \multicolumn{2}{|c|}{$2 \%$} \\
\hline
\end{tabular}

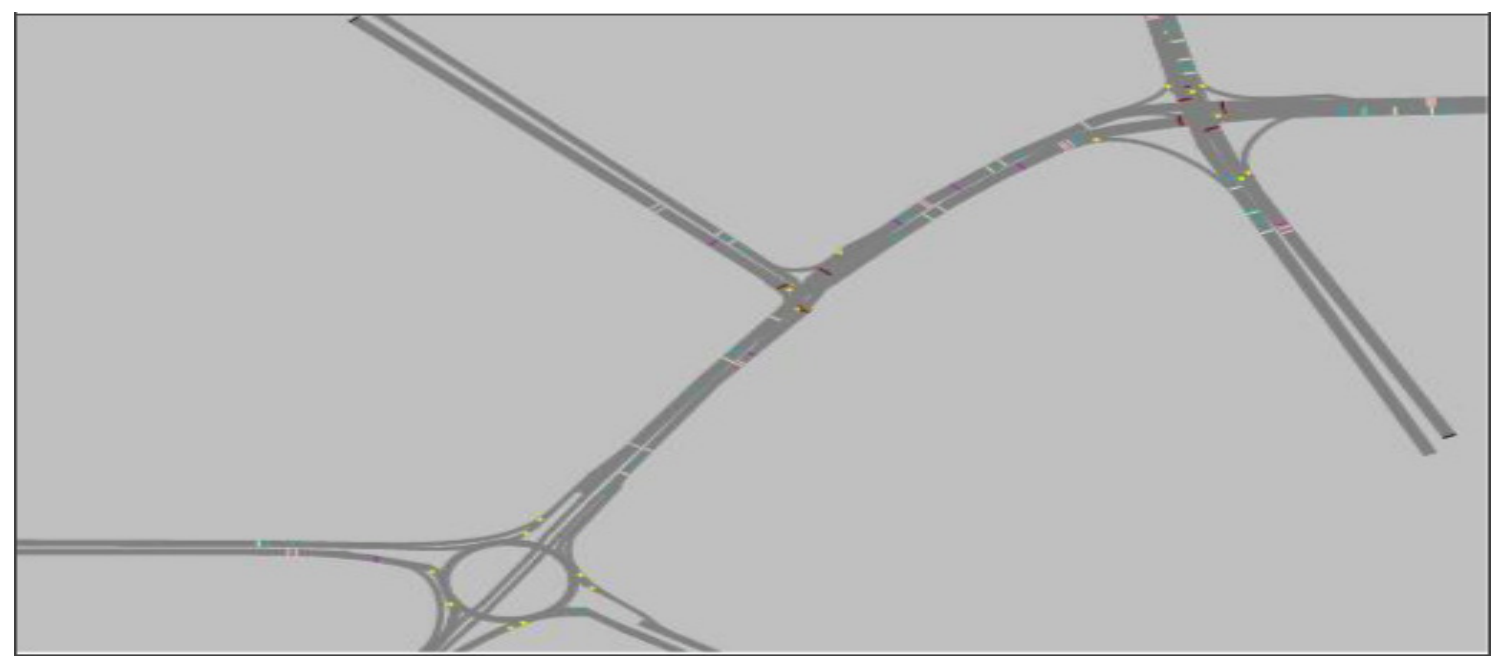

Figure 4. VISSIM base scenario Model

\section{Transit Data}

The planned transit schedules, route information along with the bus stops locations and dwell time were obtained from GAM. The transit information was based on GAM data line 2 information. It has a time headway of $15 \mathrm{~min}$. The selected corridor has no bus stop so that the impact of dwell time on the corridor operation is out of this study scope.

\section{Traffic Signal Timings}

The signal timing and phase scheme were obtained of the three intersections and coded in VISSIM.

\section{Model Development}

Base model scenario

The base model was entered to VISSIM to evaluate the current operational condition of the traffic. Base scenario was modeled using VISSIM, traffic flow along with flow movement and traffic signal timings were modeled to evaluate the base scenario performance. The base scenario using VISSIM was modeled as shown in Figure 3. The calibration model was done based on an iterative process to ensure of the output reliability. The calibration process is presented in section 5 .

\section{Optimized Arterial with Transit Signal Algorithm}

In order to evaluate the impact of TSP implementation on the case study, detectors, traffic flows and priority route were modeled on VISTRO. The developed model is shown in Figure 5. In the priority rule, the TSP algorithm was defined to prioritize transit users. This was done by minimizing the transit vehicle delay and the overall system delay using the optimization rule in section 5 .

\section{Operational Evaluation}

\section{Model Calibration}

Model calibration is a necessary step to assure the VISSIM model against the actual model. Several parameters should be adjusted including; driving behavior parameters, traffic control parameters, traffic flow characteristics. The change in these values could be based on visualization or based on field data observation. To calibrate the base model, headway, overtake reduced speed area, observed vehicles on next lane and minimum spacing were changed.

\section{Model Validation}

The calibrated models are then evaluated with a new set of data under untried conditions, including the input volumes, traffic composition, and other required data. This study adopts the Geoffrey E. Heaver (GEH) statistic 
to compare field traffic volumes with those obtained from simulation data. As a general guideline for model validation, GEH values less than 5 indicate good fit. Several simulations run with different parameter for confirmation. Table 4. shows that GEH value of the microscopic model is 2.863 which indicates a well calibrated model and represents the field traffic condition with remarkable accuracy.

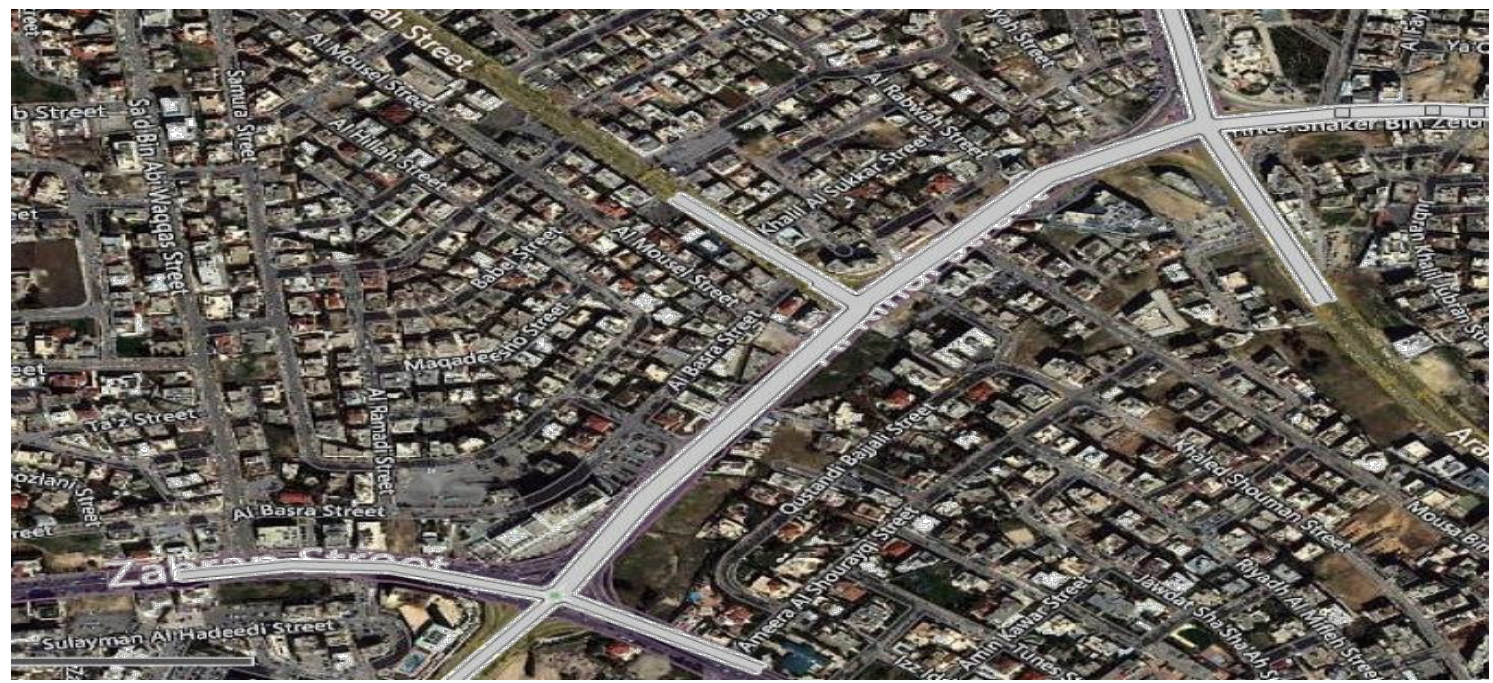

Figure 5. Base scenario Vistro model

Table 4. GEH Values of different legs of the intersections

\begin{tabular}{|c|c|c|c|c|c|}
\hline & ID & & $\begin{array}{c}\text { Field } \\
\text { Volume }\end{array}$ & $\begin{array}{c}\text { Simulated } \\
\text { Volume }\end{array}$ & GEH \\
\hline \multirow{6}{*}{$\begin{array}{c}\text { Alkindi } \\
\text { Intersection }\end{array}$} & 1 & Southbound left & 1,257 & 1,350 & 2.58 \\
\hline & 2 & Southbound right & 481 & 520 & 1.74 \\
\hline & 3 & Westbound through & 2,049 & 2,240 & 4.12 \\
\hline & 4 & Westbound right & 1,535 & 1,630 & 2.39 \\
\hline & 5 & Eastbound through & 900 & 976 & 2.48 \\
\hline & 6 & Eastbound right & 1,830 & 1,900 & 1.62 \\
\hline \multirow{12}{*}{$\begin{array}{l}\text { Wadi Saqra } \\
\text { Intersection }\end{array}$} & 7 & Eastbound Through & 1,947 & 1,860 & 1.99 \\
\hline & 8 & Eastbound Left & 897 & 810 & 2.98 \\
\hline & 9 & Eastbound Right & 500 & 570 & 3.03 \\
\hline & 10 & Westbound Through & 792 & 680 & 4.13 \\
\hline & 11 & westbound Left & 540 & 610 & 2.92 \\
\hline & 12 & westbound Right & 266 & 340 & 4.25 \\
\hline & 13 & Southbound through & 553 & 634 & 3.32 \\
\hline & 14 & Southbound left & 423 & 512 & 4.12 \\
\hline & 15 & Southbound right & 195 & 240 & 3.05 \\
\hline & 16 & Northbound through & 793 & 912 & 4.08 \\
\hline & 17 & Northbound left & 795 & 840 & 1.57 \\
\hline & 18 & Northbound right & 320 & 410 & 4.71 \\
\hline \multirow{8}{*}{$5^{\text {th }}$ Circle } & 19 & Northbound through & 687 & 780 & 3.43 \\
\hline & 20 & Northbound right & 180 & 210 & 2.15 \\
\hline & 21 & Southbound through & 1,584 & 1700 & 2.86 \\
\hline & 22 & Southbound right & 595 & 670 & 2.98 \\
\hline & 23 & Westbound through & 1,595 & 1700 & 2.59 \\
\hline & 24 & Westbound right & 595 & 612 & 0.69 \\
\hline & 25 & Eastbound through & 689 & 705 & 0.61 \\
\hline & 26 & Eastbound right & 664 & 638 & 1.02 \\
\hline
\end{tabular}




\section{Results and Discussion}

The main objective function was to minimize the delay of the total network with higher weight for transit movement. The optimization system is expressed as below:

$$
\begin{aligned}
& \sum \text { System Delay } \\
= & \text { Vehicle Delay }+2 \\
* & \text { Transit Delay }
\end{aligned}
$$

Subjected to:

$$
\begin{gathered}
0 \leq \text { cycle length } \leq 145 \mathrm{sec} \\
0 \leq \text { cummulative queue } \leq 95 \text { th } \\
0 \leq \text { offset } \leq \text { minimum cycle length }
\end{gathered}
$$

Table 4. Aggregate system results

\begin{tabular}{|c|c|c|c|}
\hline Scenario & $\begin{array}{c}\text { Base } \\
\text { scenario }\end{array}$ & $\begin{array}{c}\text { Optimized roadway with } \\
\text { signalized } \\
\text { roundabout (ORSR) }\end{array}$ & TSP with ORSR \\
\hline $\begin{array}{c}\text { Average } \\
\text { Delay } \\
\text { sec/veh }\end{array}$ & 42.12 & 38.54 & 40.73 \\
\hline $\begin{array}{c}\text { Total travel } \\
\text { Time sec }\end{array}$ & 64 & 61.09 & 63 \\
\hline
\end{tabular}

Providing simulation with the detectors to capture queue length, and Vistro with the optimum cycle length three scenarios were compared together in terms of system delay and system travel time for the entire network were compared first. Then the results for each movement were extracted and compared. Table 4 and Figure 5,6 show the aggregated results of the VISSIM analysis for the aggregate and disaggregate movements respectively, and these results include total delay and total travel time.

The results include the total travel time for the network and total delay as well for the optimize the path of BRT with applying TSP. These performance measures reflect the traffic flow and discomfort level caused to drivers on interrupted-flow facilities. It can be seen that the network delay was significantly decreased from $42.12 \mathrm{sec} / \mathrm{veh}$ on the existing network design $38.54 \mathrm{sec} / \mathrm{veh}$ on the proposed BRT with TSP with converting the 5th circle to signalized roundabout. As a result, the delay was reduced by 4 sec/veh Also, it can be seen that the total travel time has been improved by $5 \%$.

Figure 6 shows the average delay for each movement. As we compared the base scenario with the other scenarios, simulation results indicated that there is a significant drop in the movement delay as it can be seen in the ANOVA single factor analysis that is presented in Table 5. The ANOVA table covers sum of the squares (SS), mean square deviation (MS), degree of freedom (DF), F-critical value, P-value and F value. The ANOVA results indicates that the small $\mathrm{P}$-value (smaller than 0.05), with F-value is larger than F-critical which concludes that the null hypothesis is rejected, and the readjusted simulation parameters have a significant impact on the delays' movement.

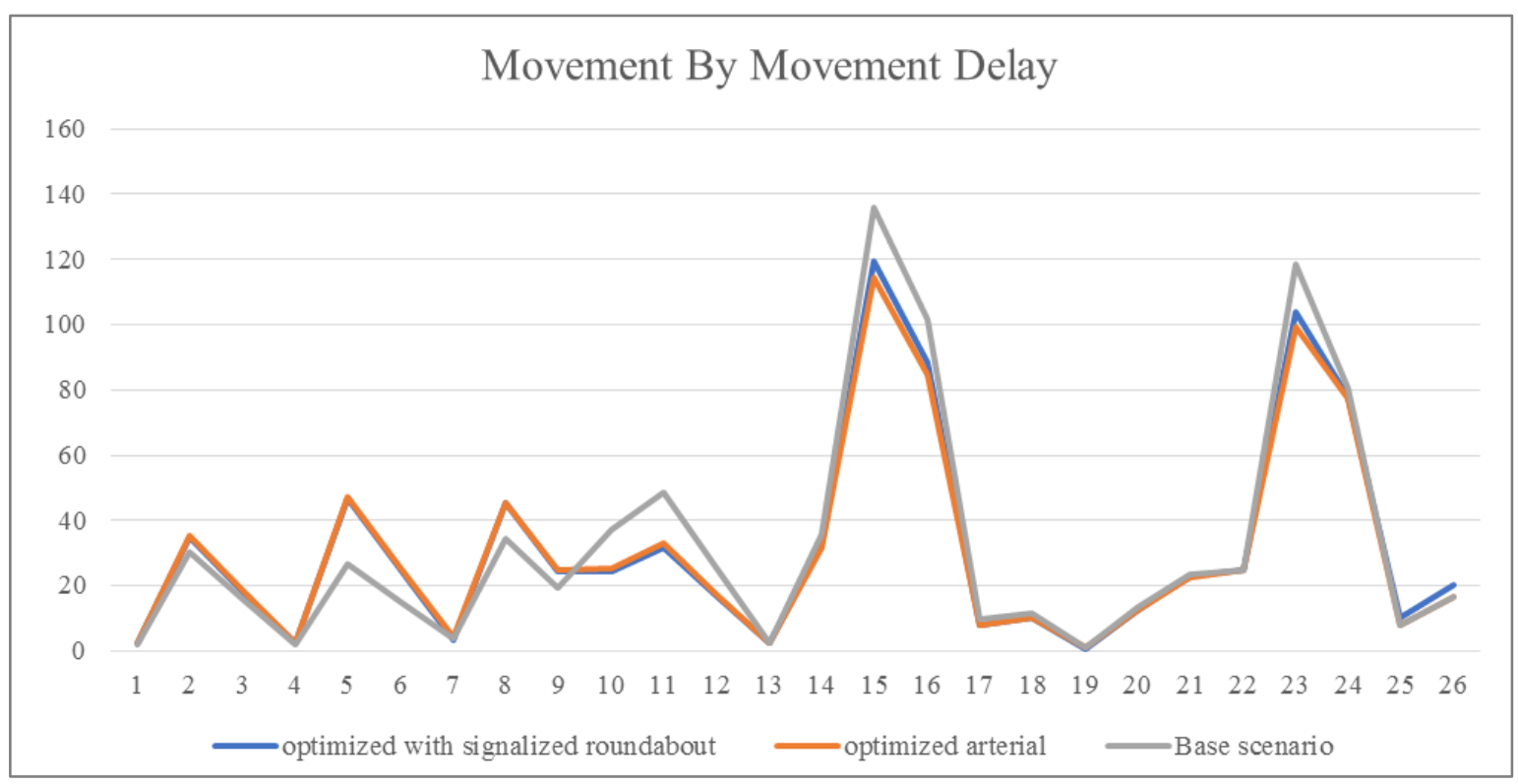

Figure 6. Movement by Movement Delay

Table 5. ANOVA Summary

\begin{tabular}{|c|c|c|c|c|c|c|}
\hline Source of Variation & SS & Df & MS & F & P-value & F crit \\
\hline Between Groups & 6235 & 3 & 2078.5 & 2.47 & 0.043 & 4.41 \\
\hline Within Groups & 84138 & 100 & 841.4 & & & \\
\hline Total & & 103 & & & & \\
\hline
\end{tabular}


Table 6. Travel Time Per Vehicle Per Movement

\begin{tabular}{|c|c|c|c|}
\hline Id & Optimized With Signalized Roundabout & Optimized Arterial & Base Scenario \\
\hline 1 & 61.54 & 62.05 & 57.09 \\
\hline 2 & 27.53 & 28.41 & 28.37 \\
\hline 3 & 142.99 & 137.96 & 159.50 \\
\hline 4 & 65.32 & 65.26 & 54.39 \\
\hline 5 & 54.13 & 50.79 & 50.66 \\
\hline 6 & 101.87 & 98.26 & 115.01 \\
\hline 7 & 122.43 & 118.11 & 137.26 \\
\hline 8 & 53.63 & 53.45 & 53.82 \\
\hline 9 & 36.11 & 36.84 & 44.66 \\
\hline 10 & 48.33 & 48.82 & 38.58 \\
\hline 11 & 37.12 & 37.25 & 38.54 \\
\hline 12 & 22.94 & 22.82 & 22.58 \\
\hline 13 & 39.31 & 37.17 & 36.92 \\
\hline 14 & 27.27 & 27.44 & 29.00 \\
\hline 15 & 22.44 & 22.55 & 22.41 \\
\hline 16 & 49.77 & 51.13 & 66.91 \\
\hline 18 & 51.73 & 50.74 & 55.01 \\
\hline 19 & 26.74 & 26.59 & 26.51 \\
\hline 20 & 46.43 & 46.83 & 41.38 \\
\hline 20 & 18.92 & 21.51 & 19.00 \\
\hline 21 & 69.13 & 69.23 & 48.79 \\
\hline 22 & 42.06 & 41.99 & 42.62 \\
\hline 23 & 100.83 & 100.71 & 103.44 \\
\hline 24 & 42.94 & 43.98 & 55.79 \\
\hline 25 & 46.96 & 47.07 & 48.08 \\
\hline 26 & 44.14 & 44.32 & 41.80 \\
\hline
\end{tabular}

Simulation results indicated that the current model is the worst in terms of the average delay and system movement; more importantly, the simulation results indicate that the proposed operating scheme, TSP with signalized roundabout, is the best scenario to accommodate the traffic volume. Also, simulation results indicate that the system delay saving ranges from $1 \%$ to $5 \%$ per vehicle. Another metric was used to evaluate the travel time per vehicle. Simulation results for the three scenarios are presented in Table 6 .

Table 6 shows the average individual vehicle travel time for each movement. As we compared the base scenario with the other scenarios, simulation results indicated that there is a significant drop in the individual travel time. Generally, simulation results indicated that the current model is the worst in terms of the individual delay and system movement; more importantly, the simulation results indicate that the proposed operating scheme, TSP with signalized roundabout, is the best scenario to accommodate the traffic volume. In addition, simulation results indicate that the saving in the individual vehicle travel time ranges from $1 \%$ to $3 \%$ per vehicle.

As seen from Figure 5, TSP implementation reduces average delay per vehicle (sec/veh) for through and right movements significantly; however, the left turning movement faces extra delay. Additionally, Table 6 shows that the travel time has been decreased for each movement except the left turning movement, and these results were verified by previous work $[1,2,15,16]$. Thus, the combination of TSP and MUT provides a better improvement in system performance in terms of system delay, queue length and speed. Next, the combination of TSP and MUT is presented in terms of network speed, movement delay, queue length and LOS.

\section{Applying MUT along Shakir bin Zaid}

Since TSP implementation has a negative impact on left turning movement. This scenario is modified the usage of optimized arterial signals with using the MUT. Basically, left turners at Wadi Saqra and Alkindi intersections are assigned to through movements as was discussed in the 
previous work by the author [13]. As MUT implemented, larger traffic volumes are assigned to the through movement, less traffic phases, and less anticipated delay.

The results of applying the TSP combined with MUT reveals some insights that are obvious in heavy traffic conditions. The results of microscopic modeling of the network performance can be reported in terms of movement speed, delay, queue length and LOS. Implementing TSP combined with MUT shows improvement network speed as compared with the base scenario. Network speed for each movement is shown in Figure 7.

Figure 7 illustrated the speed for the network movement, comparing network results with the base scenario. Applying the combination of TSP and MUT increases travel speed for different movements by $3 \%$ on average. Also, the different movement of both Wadi Saqra intersection and Alkindi has been improved significantly. Comparing LOS and queue length results for both the TSP and the combination of MUT and TSP are presented in
Table 7 and Figure 7 for LOS and queue length, respectively.

Table 7. LOS Comparison between applying the TSP and the combined TSP with MUT

\begin{tabular}{|c|c|c|}
\hline Movement O-D & $\begin{array}{c}\text { TSP } \\
\text { LOS }\end{array}$ & $\begin{array}{c}\text { The Combination of TSP } \\
\text { And MUT }\end{array}$ \\
\hline $\begin{array}{c}\text { Shakir Bin Zaid To } \\
\text { Alkindi }\end{array}$ & F & C \\
\hline $\begin{array}{c}\text { Arar To Nasser Bin } \\
\text { jameel }\end{array}$ & F \\
\hline $\begin{array}{c}\text { Alkindi To Naser Bin } \\
\text { Jameel }\end{array}$ & D \\
\hline $\begin{array}{c}\text { Nasser Bin Jameel To } \\
\text { Arar }\end{array}$ & F & C \\
\hline $5^{\text {th }}$ Circle-Macca & E & E \\
\hline $5^{\text {th }}$ Circle - Wadi Saqra & C & - \\
\hline Wadi Saqra- $5^{\text {th }}$ Circle & E & E \\
\hline Mecca- Wadi Saqra & E & B \\
\hline Mecca- $5^{\text {th }}$ Circle & D & F \\
\hline
\end{tabular}

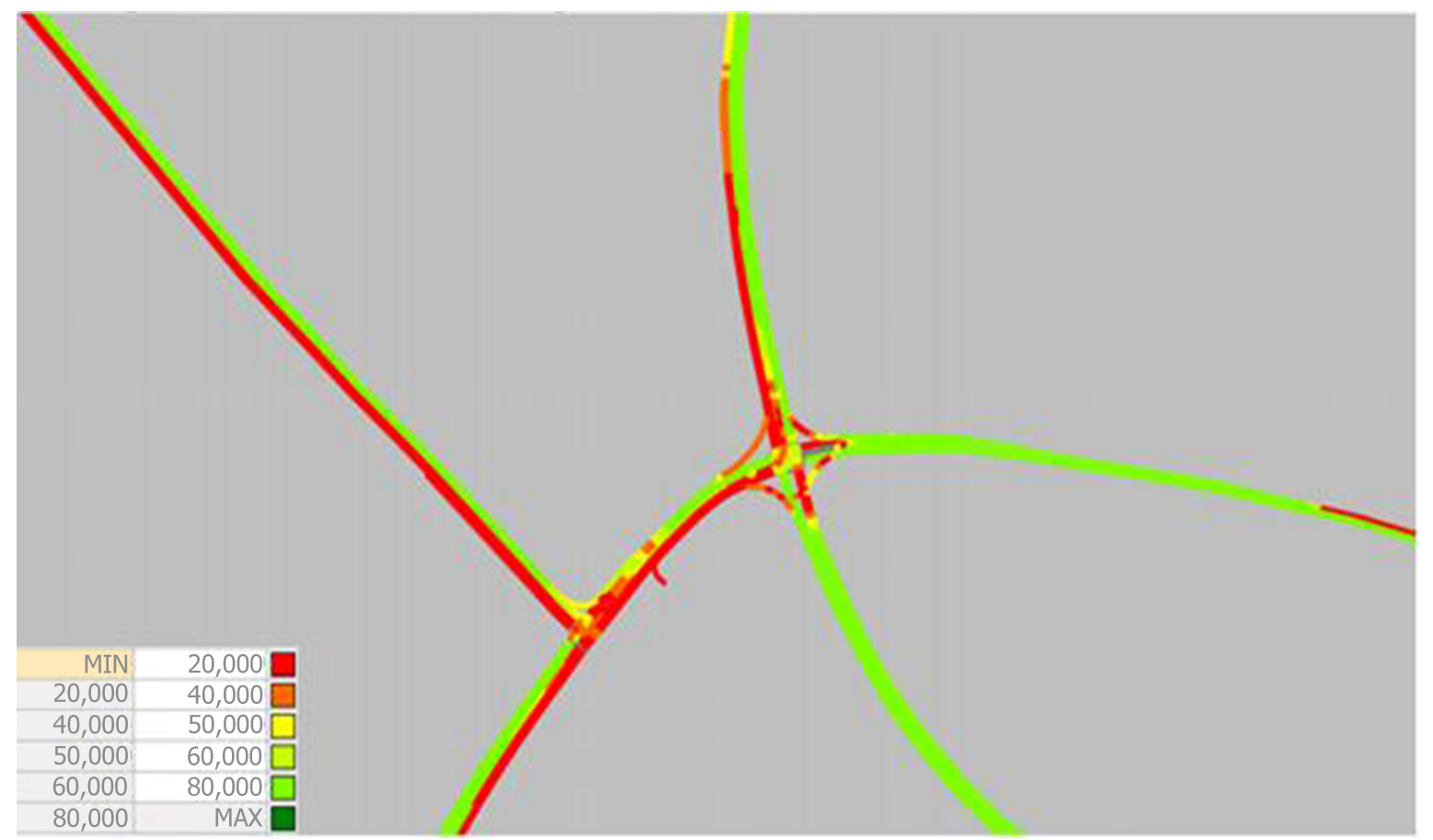

Figure 7. Network Movement Speed after implementing the combination of MUT and TSP 


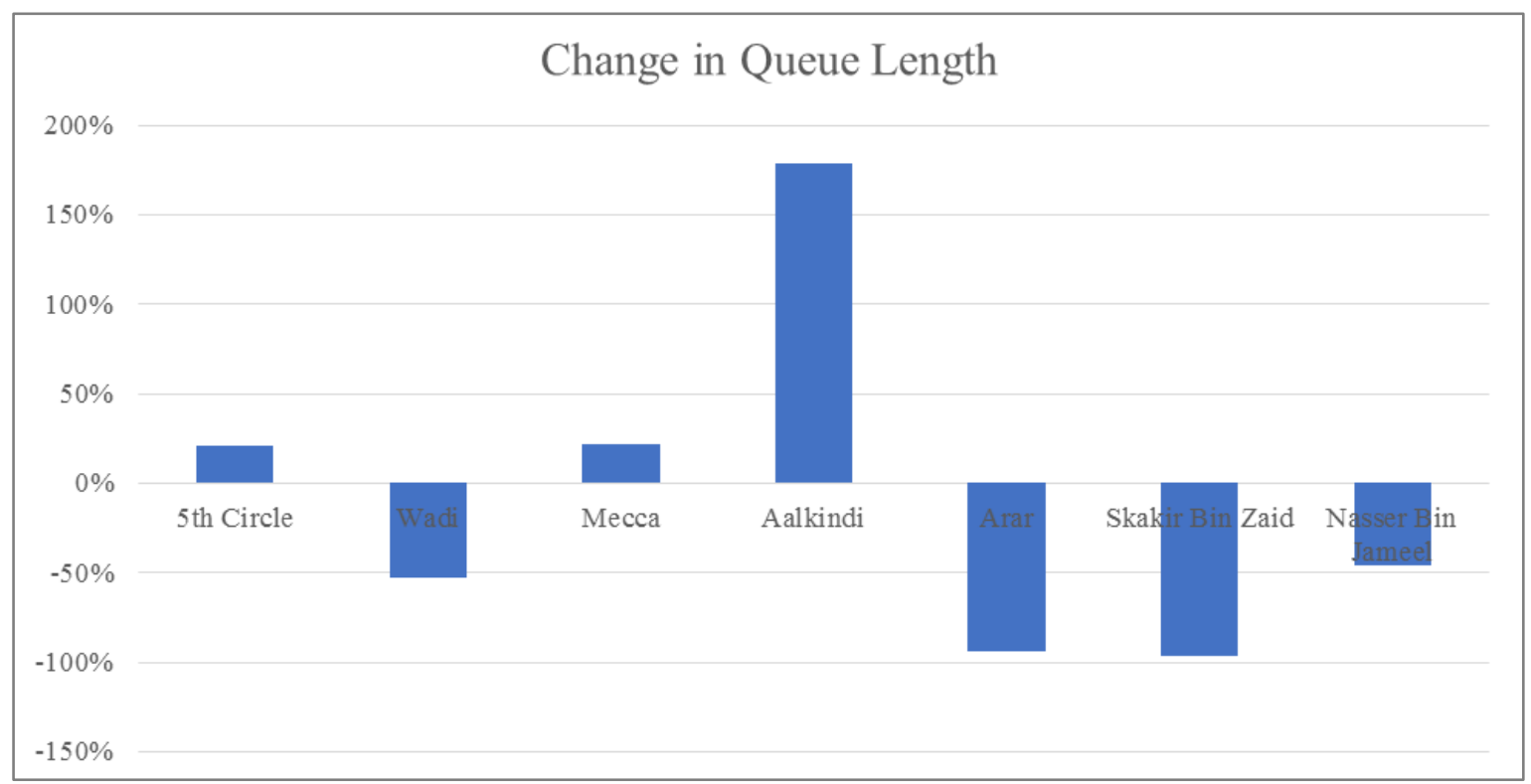

Figure 8. Change in Queue Length for Different Approaches.

Table 7 and Figure 8 illustrated the LOS and queue length for implementing the TSP and the combination of TSP and MUT. Generally, implementing the combination of TSP and MUT showed an improvement in the LOS for the different movements. Also, result indicated that applying the combination of TSP and MUT shows a significant improvement in the queue length.

\section{Conclusions and Recommendations}

This paper analyzed the operational efficiency of implementing Transit signal priority (TSP) for Bus Rapid Transit (BRT) in real case study in Jordan. The main aim for this paper is to provide decision makers with the benefit of implementing TSP. A comparison had been carried out between the base scenario, implementing optimization for the corridor, and applying the TSP to the modeled scenario 2. It can be considered as one the most significant roadways on the often congested in Amman. It connects AlShmesani area, Om Othaina area, and downtown area. The results were presented based on aggregate for the entire corridor were compared first. Then disaggregate analysis level for each movement was carried out. The results indicated that implementing TSP with the optimized arterial roadway improve system travel time as compared with the base scenario. The aggregate results showed that a significant reduction in each movement delay and travel time except for the left turning movements on Wadi Saqra and AlKindi intersections, and this was in accordance with the previous state-of-art and stat-of practice. In the second stage of analyzing, implementing the combination of TSP and MUT shows a significant improvement in LOS and queue length of the different movement .In this study, pedestrian signal was assumed to be served during the red phase of the opposing traffic. The results of this study could be strengthening if there is a pedestrian volume impact on the model.

\section{REFERENCES}

[1] E. O. Adewumi, and D. Allopi, "An Appropriate Bus Rapid Transit System," International journal of science and technology (Wallsend), 2014.

[2] C. Venter, G. Jennings, D. Hidalgo, and A. F. Valderrama Pineda, "The equity impacts of bus rapid transit: A review of the evidence and implications for sustainable transport," International Journal of Sustainable Transportation, vol. 12, no. 2, pp. 140-152, 2018.

[3] M. Ghazal. "Population stands at around 9.5 million, including 2.9 million guests," 24/12/2020. https://www.jordantimes.com/news/local/population-stand s-around-95-million-including-29-million-guests.

[4] R. J. Baker, J. Collura, J. J. Dale, L. Head, B. Hemily, M. Ivanovic, J. Jarzab, D. McCormick, J. Obenberger, and L. Smith, An overview of transit signal priority, 2002.

[5] F. Dion, H. Rakha, and Y. Zhang, "Evaluation of potential transit signal priority benefits along a fixed-time signalized arterial," Journal of transportation engineering, vol. 130, no. 3, pp. 294-303, 2004.

[6] H. Rakha, and Y. Zhang, "Sensitivity analysis of transit signal priority impacts on operation of a signalized intersection," Journal of transportation engineering, vol. 130, no. 6, pp. 796-804, 2004.

[7] S. Muthuswamy, W. McShane, and J. Daniel, "Evaluation of transit signal priority and optimal signal timing plans in transit and traffic operations," Transportation Research Record: Journal of the Transportation Research Board, no. 2034, pp. 92-102, 2007. 
[8] N. ROUPHAIL15, A. TARKO16, and J. LI17, "Traffic flow at signalized intersections," 1992.

[9] S. Yagar, and B. Han, "A procedure for real-time signal control that considers transit interference and priority," Transportation Research Part B: Methodological, vol. 28, no. 4, pp. 315-331, 1994.

[10] X. Zeng, Y. Zhang, K. N. Balke, and K. Yin, “A real-time transit signal priority control model considering stochastic bus arrival time," IEEE Transactions on Intelligent Transportation Systems, vol. 15, no. 4, pp. 1657-1666, 2014.

[11] K. Ahn, and H. Rakha, "System-wide impacts of green extension transit signal priority." pp. 91-96.

[12] W. Kim, and L. Rilett, "Improved transit signal priority system for networks with nearside bus stops," Transportation Research Record: Journal of the Transportation Research Board, no. 1925, pp. 205-214, 2005.

[13] T. Alhadidi, "Unconventional Intersection Designs for Improving Traffic Operation along Arterial Roads," University of Jordan 2015.

[14] H. Naghawi, A. AlSoud, and T. AlHadidi, "The possibility for implementing the superstreet unconventional intersection design in Jordan," Periodica Polytechnica Transportation Engineering, vol. 46, no. 3, pp. 122-128, 2018.

[15] H. S. Levinson, "Analyzing transit travel time performance," Transportation Research Record, no. 915, pp. 1-6, 1983.

[16] TRB, "Transit capacity and quality of service manual," 2013.

[17] Minseok, K., Chang, G., Rahwanji, S. (2007). Unconventional Arterial Intersection Designs Initiatives. In: IEEE Conference on Intelligent Transportation Systems, Seattle, Washington

[18] Federal Highway Administration. (2010). Alternative Intersections/Interchanges: Informational Report (AIIR), Publication FHWA-HRT-09-060. [Online]

[19] Hummer, J., Reid, J. (1999). Unconventional Left-Turn Alternatives for Urban and Suburban Arterials- An Update. In: Transportation Research Circular E-C019: Urban Street Symposium Confirence Proceedings, pp. 28-30. Dallas, TX.

[20] Bared, J., Kaisar, E. (2002). Median U-turn Design as an Alternative Treatment for Left Turns at Signalized Intersections. ITE Journal. 72(2), pp. 50-54 